\title{
ASSESSMENT OF A BOAT FRACTURED STEERING WHEEL
}

\author{
Goran Vukelic \\ Marine Engineering and Ship Power Systems Department, Faculty of Maritime Studies Rijeka, \\ University of Rijeka, Croatia
}

\begin{abstract}
During regular use of the steering wheel mounted on a boat, two cracks emanating from a fastener hole were noticed which, consequently, caused final fracture of the wheel. To determine the behavior of a boat steering wheel with cracks present, assessment of a fractured wheel was performed. Torque moments of the fasteners were measured prior to removing the steering wheel from the boat. Visual and dye penetrant inspection followed along with the material detection. Besides using experimental procedures, assessment of the fractured wheel was performed using finite element analysis, i.e. stress intensity factor values were numerically determined. Variation of stress intensity factor with crack length is presented. Possible causes of crack occurrence are given and they include excessive values of fastener torque moments coupled with fretting between fastener and fastener hole that was poorly machined. Results obtained by this assessment can be taken for predicting fracture behavior of a cracked steering wheel and as a reference in the design, mounting and exploitation process of steering wheels improving that way their safety in transportation environment.
\end{abstract}

Keywords: crack, fracture, stress intensity factor, fastener hole, steering wheel

\section{INTRODUCTION}

Imperfections in material, manufacturing faults and/ or unfavorable service conditions can easily cause flaw appearance in engineering structures. The consequential crack growth can seriously affect integrity of such structures threating the structures themselves, their users and leading to substantial financial losses. This is particularly important when dealing with possible fracture of components that are used in transportation vehicles.

Catastrophic consequence can occur if components susceptible to crack growth are used in vehicle assembly. Therefore, it is crucial to use fracture mechanics principles to assess design of such components and perform adequate material selection $[1,2,3]$.

One of such problems is discussed in this paper. Performance of a steering wheel mounted on a boat was observed. The steering wheel was of an unknown make and mounted on the boat as a replacement for the original equipment manufacturer (OEM) steering wheel. After nine years of regular marine service conditions, multiple cracks emanating from one of the fastener holes were noted. Crack propagation was monitored (only visually, without taking any relevant measurements) in the following period until the final fracture occurred. In order to numerically simulate service conditions, fasteners torque moments were measured prior to removing steering wheel from the boat. Visual inspection of cracked planes followed. Furthermore, chemical material composition and mechanical properties were determined. After that, finite element (FE) analysis was used to describe fracture behavior of the steering wheel. Obtained values of stress intensity factors gave insight into the fracture behavior and possible causes of crack occurrence and growth. Results are valuable as a reference data in the design, mounting, exploitation and for predicting fracture propagation of a steering wheel. 


\section{CRACKED STEERING WHEEL}

Multiple crack points were noticed on the in-use powerboat steering wheel after about nine years of regular maritime service conditions use. Since the steering wheel is not an OEM part, mounting was different when comparing to factory defaults. Instead of being attached by one fastener, aftermarket wheel uses an adapter to connect with steering column and it is fastened to the adapter by six fasteners. Two cracks started to emanate from one of the fastener holes causing the final fracture of the wheel, Fig. 1. Cracks started as semielliptical cracks tending to straighten their fronts as the crack propagated.

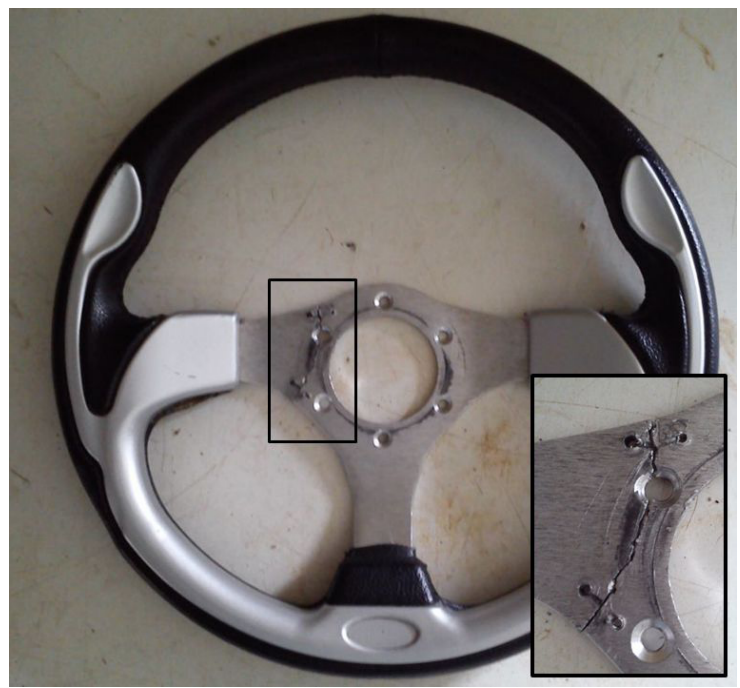

Fig. 1. Cracked steering wheel with a detail of a crack.

Geometry and dimensions of wheel skeleton (plastic lining removed) are given in Fig. 2.

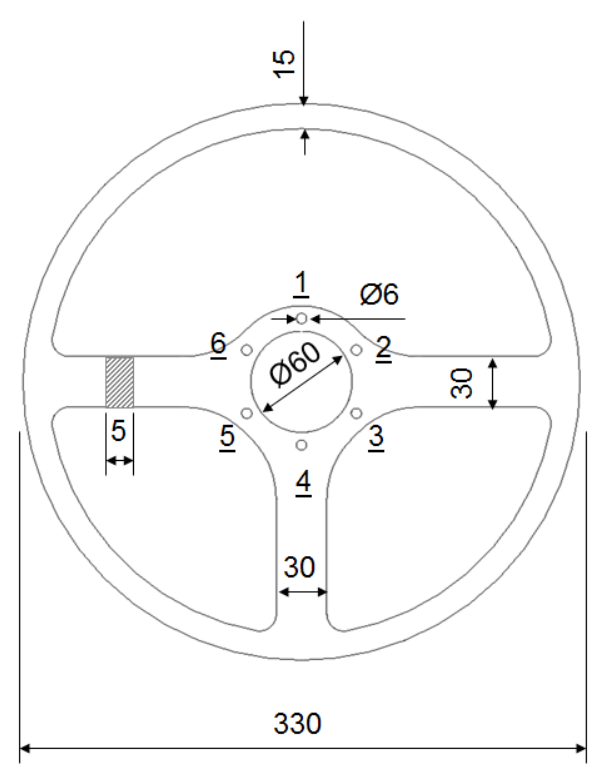

Fig. 2. Geometry and dimensions (in $\mathrm{mm}$ ) of the steering wheel.

Torque values used to tighten the fasteners were measured prior to detaching steering wheel from the column. Common marking test was performed using dial torque wrench; position of fasteners on wheel surface was marked and fasteners were then loosened and retightened again until the marks were aligned. Torques required to return fasteners to their original positions are taken as the original torques applied to fasteners (Tab. 1).

Tab. 1. Measured torque values.

\begin{tabular}{|c|c|c|c|c|c|c|}
\hline Fastener no. & 1 & 2 & 3 & 4 & 5 & 6 \\
\hline$M_{\mathrm{t}}(\mathrm{Nm})$ & 4.78 & 5.11 & 5.20 & 5.05 & 4.95 & 8.65 \\
\hline
\end{tabular}

Measured values show that the fastener mounted at the position no. 6 had relatively high torque value comparing to the other five. This excessive torque value could be due to initial mounting of the steering wheel, but it should not be neglected that it could also be a result of retightening the fastener after it loosened due to crack occurrence. However, regardless of way that is was introduced, excessive torque could initiate fatigue crack growth and final fracture.

A piece of the steering wheel was given for chemical analysis to determine the type of material. Composition of material given in Tab 2. suggests that the steering wheel was made of aluminum alloy AA 6061.

Tab. 2. Chemical composition of tested material [ $\left.\% w_{t}\right]$

\begin{tabular}{|c|c|c|c|c|c|c|c|c|}
\hline $\mathrm{Mg}$ & $\mathrm{Si}$ & $\mathrm{Fe}$ & $\mathrm{Cu}$ & $\mathrm{Cr}$ & $\mathrm{Mn}$ & $\mathrm{Ti}$ & $\mathrm{Zn}$ & $\mathrm{Al}$ \\
\hline 0.98 & 0.551 & 0.498 & 0.251 & 0.185 & 0.055 & 0.0497 & 0.0256 & 97.937 \\
\hline
\end{tabular}

When comparing obtained values with the reference [4], it can be noted that the iron percentage is below the standard value $(0.7 \%)$. The same goes for manganese percentage that is below standard value $(0.15 \%)$ and titanium which is below $0.15 \%$

AA 6061 is one of the most common aluminum alloys for general purpose use. It is a precipitation hardening aluminum alloy with good mechanical properties, widely used in automotive, aero and marine industry for various applications. Previous research [5] reveals that aluminum AA 6061 is not susceptible to stress corrosion cracking, so this effect was neglected in further research.

Mechanical properties of the mentioned material are given in Tab. $3\left(\sigma_{0.2}\right.$ - yield strength, $\sigma_{\mathrm{m}}$ - ultimate tensile strength, $E$ - elastic modulus).

Tab. 3. Mechanical properties of AA 6061.

\begin{tabular}{|c|c|c|c|}
\hline Material & $\sigma_{0.2}(\mathrm{MPa})$ & $\sigma_{\mathrm{m}}(\mathrm{MPa})$ & $E(\mathrm{GPa})$ \\
\hline AA 6061 & 55.1 & 124 & 68.9 \\
\hline
\end{tabular}

In order to reveal surface defects that could serve as crack initiation points on other fastener holes, dye penetrant test was performed. Results of the test can be seen in Fig. 3 . 

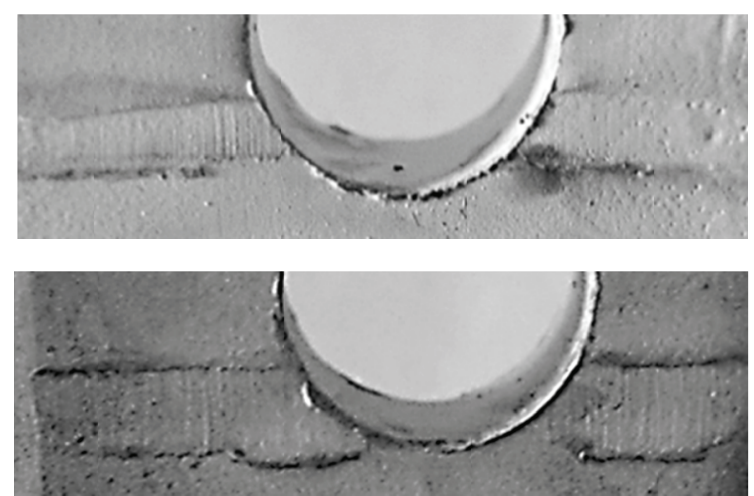

Fig. 3. Dye penetrant test results detecting defects on the back of the steering wheel surface.

Results of the performed dye penetrant test reveal defects on the back of the steering wheel surface on the edge of the fastener holes. Defects originate from poor machining of the holes and can act as crack initiation points.

\section{FRACTURE THEORY}

For materials that exhibit small-scale yielding at the crack tip, linear elastic fracture mechanics parameters can be used to assess the mentioned fracture behavior. Stress intensity factor (SIF) is one of such parameters that completely defines crack tip conditions, i.e. stress, strain and displacement values and can be connected with energy release rate $G$ [6]. Three types of SIFs - Mode I (opening), II (in-plane shear) and III (outof-plane shear), can be recognized depending on the crack opening mode. In order to determine SIF, several methods were developed, including singular integral equations [7], weight functions [8], finite element [9] or extended finite element methods [10]. Closed-form SIF solutions were developed for a number of different geometries and loads [11] and of particular interest in this work is the example of two cracks of length $a$ emanating from a round hole of radius $r$ subjected to internal pressure p, Fig. 4 .

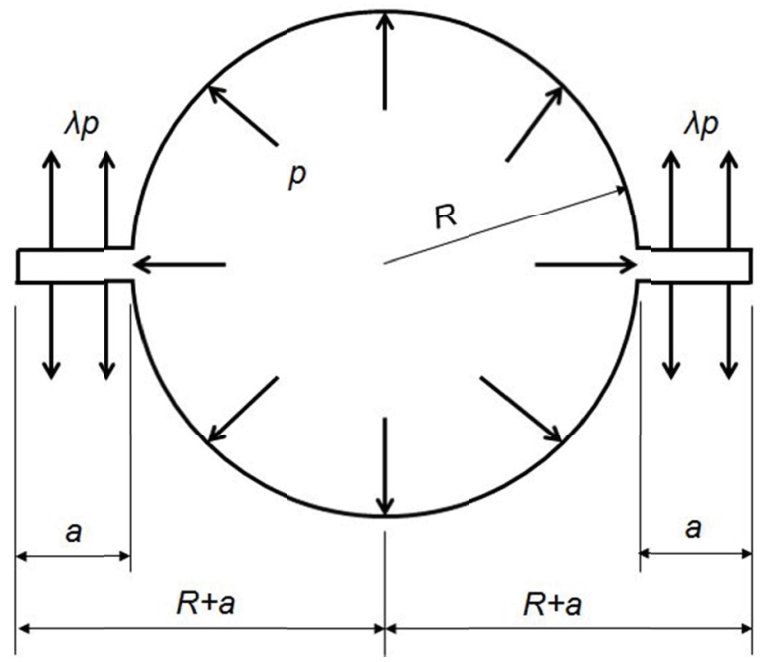

Fig. 4. Two cracks emanating from a round hole subjected to internal pressure.
Mode I SIF for example in Fig 5. according to [11] can be determined using equation:

$$
K_{\mathrm{I}}=p \sqrt{\pi a} \cdot F_{\lambda}(s),
$$

where:

$$
s=\frac{a}{R+a},
$$

and:

$$
F_{\lambda}(s)=(1-\lambda) F_{0}(s)+\lambda F_{1}(s),
$$

with $F_{0}$ and $F_{1}$ being:

$$
\begin{gathered}
F_{0}(s)=(1-s)\left[0.637+0.485(1-s)^{2}+0.4 s^{2}(1-s)\right] \\
F_{1}(s)=1+(1-s)\left[0.5+0.743(1-s)^{2}\right]
\end{gathered}
$$

Research of deriving solutions for SIFs is ongoing, especially for the applied solutions. Some earlier work includes FE alternating method for calculating SIF of cracks emanating from fastener holes [12]. Displacement extrapolation method was used in order to determine SIF for a crack emanating from a rivet hole in a plate [13]. An effort to model multiple curved cracks emanating from a circular hole using singular integral equation was made [14]. Hybrid displacement discontinuity method was used for describing interaction of two collinear circular hole cracks in infinite plate subjected to internal pressure [15]. Analytical conforming mapping method can be engaged to resolve the problem of cracks emanating from a hole in a linear elastic plate subject to in-plane tension [16]. Conforming mapping was also used for anti-plane problem of two asymmetrical edge cracks emanating from an elliptical hole [17]. Combining fracture and fatigue criterions, a mathematical model was developed to investigate the mixed mode crack growth process of a plate with two cracks emanating from drilled holes [18].

Previous research on steering wheels mainly concentrate on mechanisms of force transmission [19], impact in case of collision [20] and ergonomics [21]. Nevertheless, no previous work had been found that deals with crack occurrence or fracture of steering wheels of any kind. This paper represents a step in that direction using numerical analysis to investigate fracture behavior of cracked steering wheel and helping to design against failure in the presence of flaws.

\section{FINITE ELEMENT ANALYSIS}

In order to build a numerical model of cracked steering wheel, finite element (FE) method was used. Material behavior was considered linear elastic isotropic with properties set according to Tab. 3. Steering wheel FE model was defined according to geometry in Fig. 2, but due to symmetry only half of the wheel is modelled, Fig. 5. Symmetric boundary 
conditions are applied on the cross-section surface and only rotation round $z$-axis is allowed.

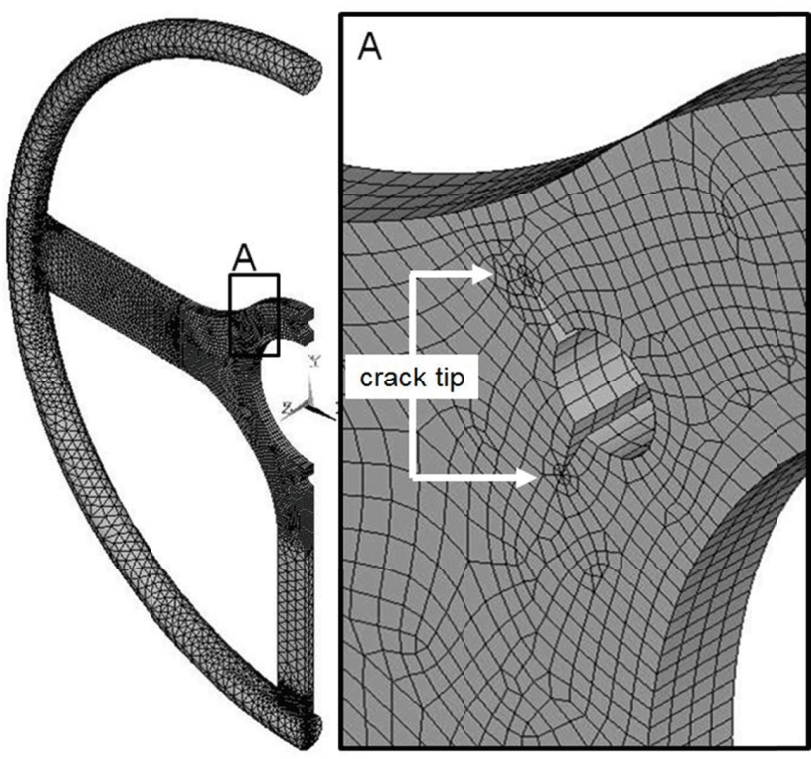

Fig. 5. FE model of boat steering wheel with a crack detail.

As for load, fastener holes are loaded according to torque loads measured in Tab. 1. The fastener surface is assumed to be smooth. Thus, it transmits only radial loads to the hole. Additionally, pressure of drivers arm resting on steering wheel is added to juncture of rim and horizontal spoke.

On fastener hole no. 6 two full-through cracks are modelled according to Fig. 1. Crack walls opening and tip deformation are, in the real case, restricted by the friction with the steering column surface, but in FE analysis this was neglected. To accommodate the singular stress field in the vicinity of the crack tips, these areas were meshed with 20 -node isoparametric brick elements collapsed to wedges. The rest of the model consists of 20-node isoparametric brick elements. Particular care was taken when meshing the area around crack tips ensuring that the mesh is fine enough to properly capture stresses and deformations. The model was meshed with about 66.000 elements with this number showing balance between accuracy of results and computer process time economy. Models with about 40.000 and 80.000 elements were tested, but failed in one of the mentioned categories.

For cracks nearly perpendicular to the loading axis, the mode II influence on the SIF is at the most $2 \%$ for the ratio suggested in [22]. Although Mode I SIFs are assumed to dominate over mode II effects, both are calculated in this work.

The FE method is employed in order to obtain SIFs because of its versatility when dealing with a vast array of different cracked structures, being standardized specimens [23] or real structures [24]. It was proved [25] that the theoretical strain/ stress singularity at the corner of a 20-node isoparametric element can be achieved by moving the mid-side nodes of the elements to $1 / 4$-point positions toward the crack tip. SIF can then be estimated for plane strain conditions from the crack-surface displacements at these $1 / 4$-points which is what was done here.

\section{RESULTS AND DISCUSSION}

Using proposed FE model and procedure, SIFs are calculated for an array of different crack lengths $a$ relative to hole radius $R(a / R=0.25,0.5,0.75,1, \ldots 3)$. Values of SIFs are normalized according to relation:

$$
K_{\mathrm{N}}=p \sqrt{\pi a} .
$$

Results are given in Fig. 6. In order to validate the FE model, results for mode I SIF were calculated according to Eq. (1). Although they cannot be quite compared because of notable differences in geometry and load, they can give some sort of confidence in using FE model. Reference SIFs obtained by eq. (1)-(5) do not take into account finite width of the plate, while that obtained by FEA do. It can be seen that the SIF values obtained by equation and FE model correspond in some way, and the difference can probably be attributed to loading conditions. Main difference is that in the cracked steering wheel there is also a mode II SIF. It can be noted that mode I SIFs dominate over mode II values. Also, there is a considerable growth of SIF with the crack changing length between $a / R=$ 0.25 and 0.5 ; after that SIF values grow steadily.

a)

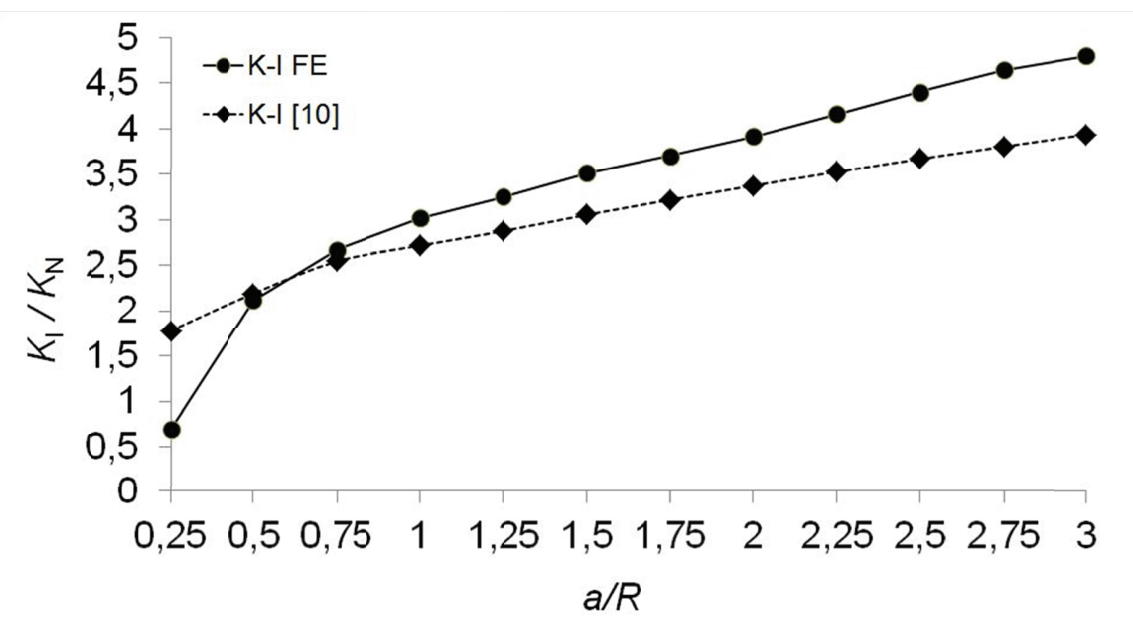




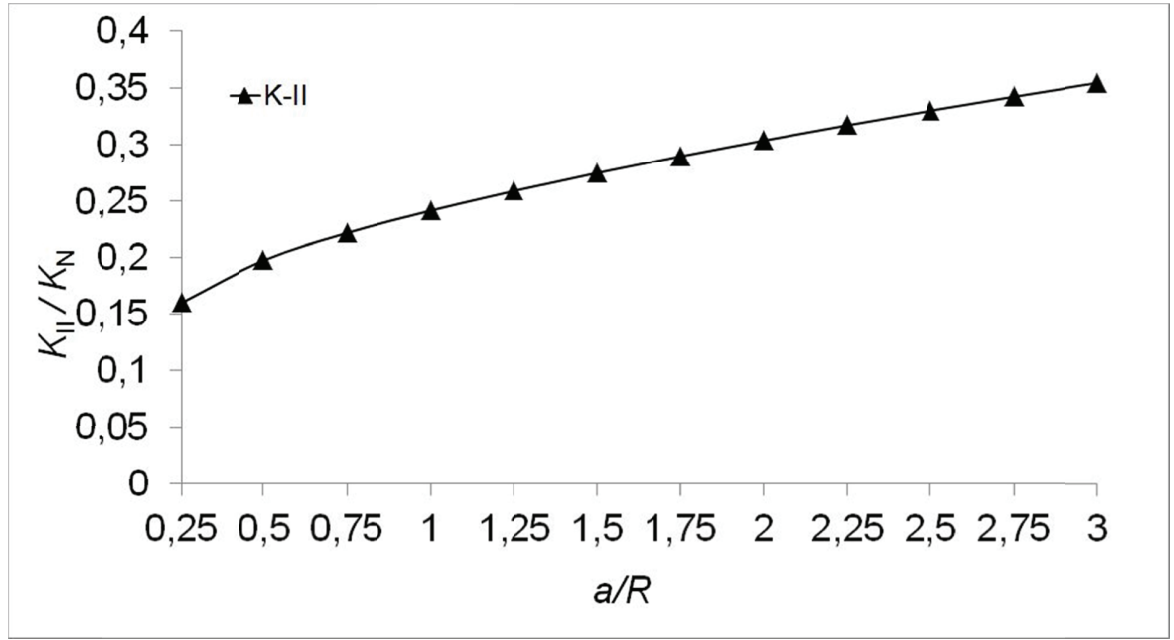

Fig. 6. Calculated normalized stress intensity factors: a) mode I, b) mode II.

\section{CONCLUSION}

Assessment of a fractured steering wheel has been performed in this paper. During regular use of steering wheel mounted on the boat, two cracks started emanating from one of the six fracture holes thru which the wheel was attached to column. After the final fracture, the wheel was examined experimentally and numerically. Analysis of chemical composition revealed that the wheel was made of AA 6061 aluminum alloy. Furthermore, the surface of wheel around holes was examined using dye penetrant test. Results showed surface defects caused by poor machining that could serve as crack initiation points. Visual inspection of the wheel revealed that two cracks emanated from a hole in which fastener was exposed to excessive torque. Using FE analysis mode I and II stress intensity factors were calculated according to different crack lengths. Obtained results give insight into the fracture behavior of a cracked steering wheel and can be found useful used in the design process, mounting or exploitation of such component improving their safety in transportation environment this way. Further study should include verification of numerically predicted crack growth with measured values obtained by monitoring the process.

\section{ACKNOWLEDGMENT}

This work has been fully supported by University of Rijeka under the project 13.07.2.2.04 "Numerical modelling of structure crack occurrence and growth".

\section{REFERENCES}

1. Gálvez Díaz-Rubio F., Cendón Franco D., Sánchez-Gálvez V.: Fracture strength of welded aluminium joints in commercial road vehicles, Engineering Failure Analysis, Vol. 13, No 2, 2006; pp. 260-270.

2. Ktari A., Haddar N., Ayedi H.F.: Fatigue fracture expertise of train engine crankshafts, Engineering Failure Analysis, Vol, 18, No 3, 2011, pp. 1085-1093.

3. Fonte M., Reis L., Freitas M.: Failure analysis of a gear wheel of $a$ marine azimuth thruster, Engineering Failure Analysis, Vol 18, No 7, 2011, pp. 1884-1888.

4. The Aluminum Association: International Alloy Designations and Chemical Composition Limits for Wrought Aluminum and Wrought Aluminum Alloys, The Aluminum Association, Arlington, USA, 2015.

5. Braun R.: On the stress corrosion cracking behaviour of 6XXX series aluminium alloys, International Journal of Material Research, Vol. 101, No 5, 2010, pp. 657-668.

6. Kyzioł L.: Analysis of fracture toughness of modified timber, Polish Maritime Research, Vol. 17, No 4(67), 2010, pp. 59-63.

7. Noda N.A., Xu C.H.: Controlling parameter of the SIFs for a planar interfacial crack in three-dimensional bimaterials. International Journal of Solids and Structures, Vol. 45, 2008, pp. 1017-1031.

8. Li J., Wang X., Tan C.L.: Weight functions for the determination of SIF and T-stress for edge-cracked plates with built-in ends. International Journal of Pressure Vessels and Piping, Vol. 81, 2004, pp. 285-296.

9. Morais A.B.. Calculation of SIFs by the force method. Engineering Fracture Mechanics Vol. 74, 2007, pp. 739-750.

10. Freese C.E., Baratta F.I.: Single edge-crack SIF solutions. Engineering Fracture Mechanics, Vol. 73, 2006, pp. 616-625.

11. Tada H., Paris P.C., Irwin G.R.: The stress analysis of crack handbook. 3rd ed. New York: ASME Press; 2000.

12. Chow W.T., Atluri S.N.. Fracture and fatigue analysis of curved or kinked cracks near fastener holes. Finite Element Analysis and Design, Vol. 23, 1996, pp. 91-100. 
13. Anand A., Sudev L.J., Lakshminarayana H.V.: Determination of SIF for a Crack Emanating From a Rivet Hole in a Plate using Displacement Extrapolation Method. Journal of Applied Sciences, Vol. 12, No. 10, 2012, 1020-1025.

14. Chen Y.Z., Lin X.Y., Wang Z.X.: A semi-analytic solution for multiple curved cracks emanating from circular hole using singular integral equation. Applied Mathematical Computations, Vol. 213, No 2, 2009, pp. 389-404.

15. Miao C., Wei Y., Yan X.: Interactions of two collinear circular hole cracks subjected to internal pressure. Applied Mathematical Computations, Vol. 223, 2013, pp. 216-224.

16. Abdelmoula R., Semani K., Li J.: Analysis of cracks originating at the boundary of a circular hole in an infinite plate by using a new conformal mapping approach. Applied Mathematical Computations, Vol. 188, No 2, 2007, pp. 1891-1896.

17. Guo J.H., Lu Z.X., Han H.T., Yang Z.: Exact solutions for anti-plane problem of two asymmetrical edge cracks emanating from an elliptical hole in a piezoelectric material. Internationa Journal of Solids and Structures, Vol. 46, No 21, 2009, pp. 3799-3809.

18. [18] Boljanović S., Maksimović S.: Mixed mode crack growth simulation with/without overloads. International Journal of Fatigue, Vol. 67, 2014, pp. 183-190.

19. Simionescu P.A., Talpasanu I.: Synthesis and analysis of the steering system of an adjustable tread-width four-wheel tractor. Mechanisms and Machine Theory, Vol. 42, No 5, 2007, pp. 526-540.

20. Altenhof W., Paonessa S., Zamani N., Gaspar R.: An experimental and finite element investigation into the energy absorption characteristics of a steering wheel armature in an impact. International Journal of Impact Engineering,Vol. 27, No. 2, 2002, pp. 197-212

21. Mossey M.E. et al.: Evaluation of four steering wheels to determine driver hand placement in a static environment. Applied Ergonomics, Vol. 45, No 4, 2014, pp. 1187-1195.

22. Cartwright, D.J., Ratcliffe, G.A.: Strain Energy Release Rate for Radial Cracks Emanating from a Pin Loaded Hole. International Journal of Fracture Mechanics, Vol. 8, No 2, 1972, pp. 175-181.

23. Newman J.C., Yamada Y., James M.A.: Stress-intensityfactor equations for compact specimen subjected to concentrated forces, Engineering Fracture Mechanics, Vol. 77, No 6, 2010, pp. 1025-1029.

24. Huang W., Garbatov Y., Guedes Soares C.: Fatigue reliability assessment of a complex welded structure subjected to multiple cracks, Engineering Structures Vol. 56, 2013, pp. 868-879.

25. Barsoum R.S.: On the use of isoparametric finite elements in linear fracture mechanics, International Journal for Numerical Methods in Engineering, Vol. 10, 1976, pp. 25-62.

\section{CONTACT WITH THE AUTHOR}

\author{
Goran Vukelic \\ e-mail: gvukelic@pfri.hr
}

Marine Engineering and Ship Power Systems Department Faculty of Maritime Studies University of Rijeka Studentska 2, 51000 Rijeka CROATIA 